\title{
Kokama: a reconquista da língua e as novas fronteiras políticas
}

\author{
Alfredo Wagner Berno de Almeida ${ }^{1}$ \\ Altaci Corrêa Rubim²
}

\begin{abstract}
Resumo
O povo Kokama, após um passado de profundas desigualdades, redesenha novas fronteiras políticas, que concorrem para a persistência da afirmação de sua identidade étnica, num futuro de autonomia e de coexistência linguística. O presente artigo apresenta a mobilização do povo Kokama em prol de suas reivindicações em relação a sua reafirmação étnica, a conquista do Registro de Nascimento do Índio(RANI), a reconquista de seus territórios, o reconhecimento das escolas Kokama e, principalmente, a reconquista da língua.
\end{abstract}

Palavras-chave: Mobilização étnica. Autoconsciência cultural. Reconquista da língua.

\begin{abstract}
Kokama people, after a past full of deep social differences rebuilds new political boundaries, that tender to the persistence of the affirmation of their ethnical identity, in a future of autonomy and linguistic coexistence. The present paper shows the Kokama people's mobilization in favor of their claims about their ethnic reassurance, conquest of the Registro de Nascimento do Índio (RANI), reconnaissance of their territories, the recognition of Kokama schools and, mainly, reconquest of the language.
\end{abstract}

Keywords: Ethnic mobilization. Cultural self-awareness. Reconquest of the language.

Há inúmeros registros da presença do povo kokama no rio Solimões e na região do Marãnon desde o século XVII, mais exatamente entre 1639 e 1691. Curt Nimuendaju no seu mapa etnohistórico assinala este período e também a data de 1710 , indicando a localização deste povo às margens daqueles grandes

1 Antropólogo. Professor-visitante da Universidade do Estado do Amazonas e coordenador do Projeto Nova Cartografia Social da Amazônia.

2 Indígena Kokama, Mestre em Sociedade e Cultura na Amazônia pela Universidade Federal do Amazonas - UFAM. Atualmente está como gerente de Educação Indígena da Universidade do Estado do Amazonas - UEA, pesquisadora do Projeto Nova Cartografia Social da Amazônia e Assessora da Gerência de Educação Escolar Indígena da Secretaria Municipal de Educação de Manaus. 
rios (Freitas 2002:28). Os comentadores regionais relatam ainda hoje que os kokama constituíam um povo que vivia em constante movimento. Este processo de deslocamento do povo Kokama tem sido sempre explicado como atrelado a conflitos na busca de terras para plantio e de águas para o exercício da pesca. São inúmeros os dados etnográficos concernentes aos Kokama, nas descrições de missionários, viajantes, cronistas, naturalistas, historiadores e administradores coloniais, que apontam estes sucessivos deslocamentos geográficos.

Durante séculos, os Kokama se empenharam em grandes contendas, resistindo tanto a outros povos, quanto à ação colonizadora do estado dinástico e da Igreja, cujos empreendimentos extrativistas e de "agricultura tropical" disputavam seus recursos hídricos e florestais. A usurpação de seu território foi acelerada, notadamente após o início da segunda metade do século XVIII, com as concessões de terras realizadas pela política pombalina na Amazônia. As atividades produtivas tradicionais foram seriamente afetadas neste esforço de guerra e os instrumentos de caça e de pesca foram transformados em armas defensivas frente ao poder bélico dos colonizadores. Foram tempos de lutas e resistência munidos, somente, com arcos, flechas e zarabatanas. Durante séculos de entreveros consecutivos e desiguais, o povo Kokama foi submetido a duras pressões colonialistas e conheceu outras guerras, como as provocadas pelas medidas integracionistas dos governos coloniais e republicanos. Consoante tais medidas os estabelecimentos de ensino foram largamente utilizados na "educação dos índios", desestruturando-os culturalmente, como deixa entrever a situação dos kokama (Rubim 2011).

A obrigatoriedade do ensino de português, a expulsão dos jesuítas, o enfraquecimento das outras ordens religiosas e as demais exigências preconizadas pelo Diretório instituído pelo Marques de Pombal, em agosto de 1758, coibindo o sistema de alianças e proibindo o uso do nheengatu e das línguas indígenas, que estava apoiada no princípio "Língua do Príncipe", ou seja, o português, resultou na veneração e na obediência ao poder real, inibindo conflitos e resistências. Reprimir as línguas nativas e demais práticas culturais tornou-se um instrumento decisivo para o funcionamento econômico do sistema agrário-exportador ancorado em grandes plantações monocultoras de algodão e cana-de-açúcar e na imobilização da força de trabalho ${ }^{3}$. A escola para indígenas, mantida como instrumento da ação colonizadora, voltou a ser implementada por ordens religiosas, após o declínio da política pombalina.

3 A uniformidade linguística em torno da língua portuguesa nas grandes plantações de cana-de-açúcar e algodão parece ter sido um severo mecanismo de controle sobre os trabalhadores escravos. Sua aplicação ocorreu pela dispersão de escravos de diferentes etnias por diferentes fazendas, evitando agrupamentos de membros de uma mesma etnia, que faziam uso de uma mesma língua, numa mesma unidade de produção. Para maiores informações consulte-se Almeida (2007). 
O povo Kokama, depois de repetidas tentativas de massacres físico, social e cultural, foi compelido a enviar suas crianças para estas escolas dirigidas pelas ordens religiosas. Os resultados foram nefastos. Tão nefastos que até as lideranças atuais reconhecem esse fato como prejudicial para identidade Kokama: "quando saíam das escolas as crianças não queriam mais se considerar indígenas”, (Pereira 2011). Os pais já não passavam para seus filhos sua língua e as ditas "tradições". Os efeitos da interdição da língua indígena consistiram em fatores preponderantes para que a transmissão da língua Kokama ficasse interrompida. Consoante os relatos obtidos no decorrer da pesquisa que ora estamos realizando, as crianças entendiam o que os pais e avós falavam, mas se recusavam a se expressar na língua. Uma geração falava e entendia a língua Kokama (os falantes da Língua Kokama), a outra geração apenas entendia (os ouvintes da Língua Kokama), a geração seguinte lembrava-se de conversas de seus pais quando pequenos (eram lembradores da Língua Kokama) e a recente geração em sua maioria não fala, fluentemente, nem entende (atualmente são os aprendizes da Língua Kokama) (Rubim 2011).

De maneira concomitante, sucedeu o que foi considerado o "desaparecimento" do povo Kokama. Um período obscuro na história deste povo, em que praticamente cessam as informações sobre ele. Os pais já não falavam a língua, seus filhos viviam e conviviam com tios, tias, primos e primas, mas não se reconheciam como Kokama; casavam com pessoas de outros povos, sobretudo os Ticuna e passavam a se identificar como tais. Foi um prolongado tempo de negação e de existência atomizada, cujas manifestações culturais encontravam-se submetidas àquelas de outros povos, principalmente os Ticuna, cuja expressão demográfica e territorial os tornavam politicamente hegemônicos. Os Kokama viviam como se estivessem condenados a um encapsulamento perene sob a identidade e a língua dominante dos Ticuna. Suas unidades sociais - comunidades - e os indivíduos que as integravam não reconheciam a si mesmo e nem eram reconhecidos como Kokama.

Somente na década de 1980-90, o povo Kokama voltou ao cenário nacional. Segundo a interpretação de Freitas, esse surgimento deu-se pelo fato dos Kokama frequentarem as reuniões e assembleias do povo Ticuna (Freitas 2002). As mobilizações étnicas ${ }^{4}$ dos Ticuna propiciaram um fortalecimento político deste povo, através de uma luta pela demarcação de suas terras. Um dos efeitos deste processo mobilizatório, de intensas relações conflituosas com os aparatos de poder do Estado, foi à consciência de si mesmo por parte dos Kokama, que igualmente se fortaleceram e passaram de maneira concomitante a se distinguir dos Ticuna, também reivindicando suas próprias terras e políticas de saúde e educação diferenciadas. Esta articulação entre diferentes

4 Para um aprofundamento do conceito de mobilização étnica e de suas possibilidades analíticas, correlacionando as relações das identidades culturais e étnicas com os fatores econômicos, consulte-se Bourgois (1993:53-64). 
povos indígenas corrobora a proposição de Barth (2000) de que as fronteiras passam a ser delimitadas nas relações sociais que reforçam as identidades coletivas e não necessariamente no isolamento. Os agentes sociais produzem o significado do fator étnico e o reforço de sua identidade coletiva na interação social (Barth 2000).

As relações entre os Ticuna e os Kokama foram ambíguas durante longo tempo, mas essenciais para o aprendizado político e para propiciar condições para a emergência da identidade coletiva Kokama. Embora os Ticuna tenham procurado inibir o processo de autodefinição dos Kokama, o processo mobilizatório pela demarcação dos territórios contribuiu para a intensificação de relações sociais, cujos resultados escaparam à sua vontade política. $\mathrm{O}$ fortalecimento dos Ticuna produziu assim condições de possibilidades para a emergência das mobilizações étnicas dos Kokama, que passaram a construir uma existência coletiva. Para Deleuze (2005), as análises de Foucault consideravam o "poder como relação de forças" (Deleluze 2005:78). O quantum de força de cada um afeta as relações políticas, de um modo especial e, assim, como afeta, é afetado. Em resumo, as relações de forças entre povos indígenas do Alto Solimões, possibilitaram perceber que a hegemonia Ticuna passou a ser "ameaçada" com o ressurgimento do povo Kokama, expresso por uma existência política.

Deste modo, no final da década de 1990, muitas comunidades Kokama se mobilizaram segundo uma política de identidade, afirmando sua cultura e passando a reivindicar e a ocupar seus territórios na região do Alto Solimões. Este processo de auto-reconhecimento étnico dos Kokama, revelando uma profunda autoconsciência cultural, ao convergir para direitos territoriais, provocou grande tensão nas relações do povo Ticuna com a sociedade nacional e ampliou as mobilizações étnicas face ao Estado. Considerando a interpretação "transactionalist" ${ }^{5}$ de Barth tem-se que a etnicidade explicita a autodefinição bem como a definição por parte de outros. Em outras palavras a mobilização política dos Kokama em conjunto com os Ticuna, cuja língua também se expressam ${ }^{6}$, foi fundamental para a reafirmação e reconhecimento

5 Vide Tal abordagem, que considera o grupo étnico como uma unidade de atribuição em que as fronteiras sociais é que garantem a persistência do grupo, distingue-se da "primordialista" e da "instrumentalista", criticando-as. A delimitação destas fronteiras não se restringe a fatores físicos, geográficos, mas compreende também os fatores simbólicos como a língua e os conhecimentos gastronômicos, dentre outros, que concorreriam para perpetuar aquele povo. Vide "Introduction" (Hutchinson \& Simth 1996:3-14).

6 Para um aprofundamento destas situações relativas a "comunidades políticas formadas com povos de línguas diferentes” leia-se Raisons Politiques-études de pensée politique, n.2,mai-juillet de 2001, cujo número especial é intitulado "La République des langues" e tem 12 artigos de autoria de: Dany-Roberto Dufour, Marc Crépon, Pierre Bourdieu, Abram de Swaan, Claude Hagège, Marc Fumaroli, Immanuel Wallerstein, Rainer Rochlitz, Claude Javeau, Emmanuelle Vignaux e José Woehrling dentre outros. 
de uma identidade contrastante, capaz de romper com o encapsulamento a que foram historicamente submetidos.

Em decorrência, os Kokama passaram a si posicionar autonomamente nas suas relações com instituições públicas. A Fundação Nacional do Indio (FUNAI), entrementes, não os reconhecia formalmente. Muitas indagações neste sentido foram levantadas pelos técnicos da FUNAI: "quem é este povo? Qual a sua língua? Como estão organizados politicamente?” Uma das respostas mais frequentes para aclarar dúvidas da burocracia é de que "não são Ticuna e não vivem como Ticuna". Esta recusa de reconhecimento e a suspeição que cerca as perguntas consistem num grave problema enfrentado pelos kokama até o dia de hoje.

Abre-se um tempo de tensas relações políticas marcadas por recorrentes tentativas de convencimentos, de esclarecimentos e de respostas. Um dos resultados destas tensões tem se tornado mais perceptível, pois a mobilização Kokama em prol de seu reconhecimento étnico passou a surtir efeito e uma de suas principais reivindicações foi atendida com os laudos linguísticos e antropológicos elaborados por pesquisadores acadêmicos e da própria FUNAI. As discussões entre professores Kokama universitários e lideranças indígenas tem ampliado, neste momento o espectro de relações dos Kokama e aumentado seu conhecimento sobre as realidades localizadas, alargando seu próprio capital intelectual. Técnicas de mapeamento, viagens sucessivas a diferentes pontos de seus territórios e realização de eventos como oficinas de mapas, audiências e assembleias específicas de seu próprio povo, discutindo perímetros e características específicas de ecossistemas, evidenciam esta etapa do processo mobilizatório. Algumas lideranças Kokama no decorrer deste processo tem se capacitado enquanto dirigentes e adquirido atributos técnicos e habilidades de liderança, que autorizam aproximá-los do que Foucault conceitua como intelectuais específicos.

A interpretação de Foucault sobre a estrutura do poder aponta para relações de força e as delimitações que elas estabelecem, como diria Deleuze: "torna fácil ou difícil, ampliar ou limitar” (Deleuze 2005:78). Tais características podem ser observadas empiricamente no cotidiano dos Kokama, principalmente quando se dirigem à FUNAI para requerer o Registro Administrativo de Nascimento do Indio-RANI, documento que ratifica a identidade étnica do indígena requerente. São diversas as reivindicações para a obtenção do RANI e ocorrem de diferentes formas do Baixo Rio Negro ao Alto Solimões. Cada povo engendra seus próprios mecanismos de afirmação. No caso dos Kokama com o seu ressurgimento na cena política, na década de 1980 (Freitas 2002), ocorreram mobilizações em torno de direitos territoriais, de educação diferenciada e de saúde, nas quais eles reafirmavam coletivamente sua identidade étnica diante de outros povos indígenas e do próprio Estado. 
Com efeito, faz sentido a afirmação do senhor Felisberto Maurício, 71, Kokama, uma das lideranças tradicionais da aldeia Nova Jordânia em São Paulo de Olivença/AM: "fui para uma apresentação em Belém e lá falei que os Kokama ainda existiam, falei na minha língua e aí, realmente acreditaram que existia Kokama" . Esse depoimento ratifica o processo do reconhecimento da identidade Kokama em diferentes espaços sociais da sociedade nacional. O reconhecimento étnico do povo Kokama não foi, entretanto, abrupto. Foi ocorrendo gradativamente pelo esforço mobilizatório de convencimento dos técnicos da FUNAI. Os kokama passaram ademais a se organizar mais incisivamente, após a Constituição Federal de outubro de 1988. Importa sublinhar que ainda assim permanece, nos dias de hoje, a reivindicação pelo RANI, bem como os grandes obstáculos para obtê-lo.

Para efeitos analíticos, tomamos como referência empírica a comunidade Kokama Nova Esperança ${ }^{8}$ que, desde 2005, inicia um processo de reorganização social, com presença ativa do movimento indígena de Manaus, realizando e participando de assembleias, oficinas e encontros e reivindicando o reconhecimento étnico da FUNAI, por meio do RANI.

O RANI consta da pauta de reivindicação de vários povos indígenas, tais como: Kokama, Kaixana, Kambeba e outros. A busca pelo reconhecimento levou os Kokama a tomarem a decisão de realizar uma assembleia geral, na qual se discutiu a escolha dos nomes indígenas de seus membros. Depois desse acontecimento houve uma oficina de trabalho, focalizando a língua Kokama com a presença de um linguista do CIMI $^{9}$ em que foi também discutida a escolha dos nomes indígenas.

Num dia ensolarado, de acordo com muitos relatos, os Kokama da comunidade Nova Esperança se reuniram descontraidamente sob a sombra das árvores. O então cacique Sebastião Castilho Gomes, Kokama, nessa reunião, explicou o significado de seu nome indígena e sua importância para o reconhecimento étnico pelos órgãos representativos. Nessa perspectiva, os membros da comunidade começaram a se manifestar, falando que eles já possuiam nomes indígenas, mas não tinham RANI, outros falavam que seus avós e bisavós tinham nomes indígenas, mas não falavam muito sobre o assunto, e que eles gostariam de ter um nome próprio, em sua própria língua.

O mencionado cacique pediu para o professor Kokama, Orígenes Corrêa Rubim, auxiliar os membros da comunidade na escolha de seus nomes. Assim, homens, mulheres e crianças foram "rebatizados" ou renomeados na própria língua Kokama como se pode depreender dos exemplos abaixo:

\footnotetext{
7 Entrevista realizada, 30 de agosto de 2010, na aldeia Nova Jordânia. 8 Localizada no Ramal do Brasileirinho, $\mathrm{km}$ - 4, Ramal - 8; Puraquequara II, Manaus-AM. 9 Conselho Indigenista Missionário. Linguista e padre Ronaldo MacDonell, que realiza oficinas sobre Línguas indígenas com povos indígenas do Amazonas.
} 


\begin{tabular}{|l|l|}
\hline $\begin{array}{c}\text { Nomes de Mulheres kokama/ } \\
\text { TxiraWajna }\end{array}$ & \multicolumn{1}{|c|}{$\begin{array}{c}\text { Nomes de Homens kokama/ } \\
\text { TxiraÑapjtsara }\end{array}$} \\
\hline Kuaratxi - Sol & Jauaratinin - Cachorro Branco \\
\hline Sisa - Flor & Tuan - Grande \\
\hline Ja - Coração & Itaki - Pedra \\
\hline Iña - Bodó & Mapa - Abelha \\
\hline Tata - Fogo & Ywytu - Vento \\
\hline Uni - Água & Uyaru - Feroz \\
\hline Wajna - Mulher & Mitxu - Gato \\
\hline Kwema - Amanhecer & Txiri - Grilo \\
\hline Amana - Chuva & Mjara - Macaco \\
\hline Majnuma - Beija-flor & Uruma - Pato \\
\hline
\end{tabular}

Fonte: Ata de registro de nomes dos membros da comunidade Nova Esperança Kokama do ramal do Brasileirinho/Manaus-AM.

Estes foram alguns dos nomes escolhidos naquele dia que marcou a autoafirmação étnica dos Kokama em Manaus. Na comunidade, naquele momento residiam 15 famílias, mas associadas há 86 , sendo 15 famílias que residem na comunidade e 71 família que residem fora da comunidade. (Abro um parêntese para falar que a comunidade saiu desse local e passou a residir em sua própria terra, sendo no mesmo km-8, ramal-8 do Brasileirinho, Puraquequara II, medindo 55x115m, doada para a Associação dos Índio Kokama Residentes no município de Manaus - AKIM, por Júlio Dias Batista, kokama, sua esposa Maria Lidia Dias de Sena Batista, kokama e pela Suframa em janeiro de 2012).

$\mathrm{Na}$ sequência dos acontecimentos, a FUNAI passou a conceder os RANI a quem levasse a cópia do RANI dos pais ou avós. Quem não tivesse esse documento necessitaria voltar à sua aldeia de "origem" para tirar o RANI num posto da FUNAI mais próximo. Ou então, num reducionismo genealógico, informavam que, em tempo oportuno, iriam fazer uma "pesquisa antropológica" na aldeia de "origem". A "arqueologia genealógica" e seus fundamentos primordialistas prosseguem como critério fundamental para a burocracia da FUNAI.

Conforme as entrevistas realizadas, constata-se que os funcionários estabeleciam um prazo extremamente curto, entre um a três meses, para realizar tal pesquisa. Passado este período, quando os kokama voltavam para ver o resultado, a pesquisa ainda não havia sido realizada. O cacique, Sebastião Kokama, depois de muitas reivindicações não atendidas, para tirar o RANI do seu povo, decidiu que só iria sair do órgão, quando suas reivindicações fossem 
atendidas. Esta ocupação abriu uma via de negociação. Os técnicos da FUNAI, o coordenador e o cacique se reuniram e decidiram atender às reivindicações do povo Kokama em Manaus. Atualmente, as86 famílias associadas à AKIM, portadora do RANI. Vale ressaltar que para os kokama da comunidade Nova Esperança do Brasileirinho, o RANI representa a conquista do reconhecimento étnico, diante da FUNAI e pelas demais instituições. O documento é essencial para se obter os benefícios sociais, previstos em lei, que a Funai administra, e de igual modo contém a possibilidade de reconhecimento de direitos territoriais.

Nesse sentido, a mobilização dos Kokama para adquirir o Registro de Nascimento do Índio, é extensiva ao Médio e ao Alto Solimões. Nos municípios em que os conflitos étnicos se intensificam de forma "silenciosa" e se configuram em espaços de relações culturais específicas, relativizando o conhecimento detido pelas etnias dominantes, no caso do Alto Solimões, Tikuna, esta mobilização tende a se consolidar.

O período no qual os Kokama ficaram em silêncio, ou, como dizem, permaneciam nas "franjas" dos Ticuna, eles evitavam se identificar como povo indígena. No momento atual os agentes sociais redefinem seus processos de organização sociocultural e política, construindo socialmente “territorialidades específicas de pertencimento coletivo"(Almeida 2008), através do fortalecimento dos mecanismos de representação que conduzem mobilizações pelos direitos territoriais.

Pode-se asseverar que as relações interétnicas entre Tikuna e Kokama consistem em relações ambivalentes que, por um lado, em determinados momentos, foram essenciais para a "consciência" Kokama, na aprendizagem da resistência identitária, e por outro, representaram um empecilho para o processo de autodefinição e seus desdobramentos.

Enquanto para os povos Tikuna, Tukano e Baniwa, os agentes se organizam e conquistam cargos públicos, participam de eleições municipais e realizam experiências que definem as suas práticas políticas, para os Kokama a política consiste principalmente em formar professores indígenas e garantir sua permanência nas escolas, ministrando aulas e reforçando os laços linguísticos nas aldeias e em suas comunidades. A estratégia preferencial em torno da educação diferenciada e da língua própria consiste numa escolha deliberada, objetivando a coesão social necessária a uma ação política e coletiva.

Nessa perspectiva, há toda uma mobilização desde o baixo Rio Negro, Médio Solimões e Alto Solimões para o reconhecimento de sua escola pelo MEC, como escola indígena. Após muitas mobilizações, no Baixo Rio Negro, saiu o decreto $\mathrm{n}^{\circ} 1.394 / 11$ aprovando o reconhecimento do professor e da escola indígena no município de Manaus. Por meio do edital 2/2012 foi realizado um processo seletivo para a contratação de professores indígenas para o "ensino de língua e cultura” em Manaus. Foram 23 classificados de várias etnias, como; 
Tikuna, Sateré-Mawé, Karapãna, Baré e outros, dos quais dois foram Kokama. Vale ressaltar que o "ensino da língua e da cultura" é realizado na comunidade Nova Esperança Kokama desde 2005.

No Médio Solimões, o processo de reivindicação escolar indígena kokama é mais moroso do que nas demais regiões. Atualmente, as oficinas da língua kokama começam também a ser realizadas, nos municípios de Fonte Boa (oficina CIMI $^{10}$ ) e de Jutaí (oficina PDPI ${ }^{11}$ ). Nestes municípios já foi iniciado um processo de mobilização, reivindicando a contratação de professores Kokama.

No Alto Solimões, as mobilizações étnicas são intensas e, devido à pressão organizativa das associações, conseguiram conquistar vagas específicas para professores Kokama, por meio de concurso público. Tal experiência se deu no Município de São Paulo de Olivença, que possui 32 comunidades ou aldeias representadas na Associação das Comunidades Kokama de São Paulo de Olivença (ACIK). No concurso realizado em 2010, a prefeitura municipal abriu vagas para professores indígenas de seus respectivos povos: Kokama, Kambeba, Kaixana e Ticuna. Os Kokama se organizam com base no critério de lugar e com base nos aparatos jurídicos e na relação com suas formas culturais, evocando o passado e acentuando sobremaneira a "revitalização" por meio da educação diferenciada e da valorização das lideranças que falam a língua materna. Este movimento se estende do Baixo rio Negro (Kokama em Manaus) até Tabatinga (Alto Solimões).

Sob a égide jurídica as lideranças Kokama dão ênfase, portanto, à educação indígena. Para elas a "construção da identidade indígena passa pela formação da Escola Indígena”. No município de São Paulo de Olivença, a presença dos Kambeba, Ticuna, kaixana e kokama indica que a cidade está em processo de expansão, adentrando inclusive nas terras indígenas. Tem-se o registro destes intrusamentos nas comunidades indígenas de Nova Jordânia, São Sebastião da Colônia, Santa Maria da Betânia e São Joaquim. Estas comunidades são formalmente consideradas "rurais" e os representantes políticos reivindicam para elas a categoria de "bairro", passando a se localizar no perímetro urbano e a fazer parte do patrimônio municipal.

A estratégia utilizada pelos kokama de São Paulo de Olivença para frear tal ação expansionista, foi solicitar o reconhecimento oficial das escolas em

$10 \mathrm{O}$ linguista e padre Ronaldo MacDonell, do Conselho Indigenista Missionário (CIMI), realiza oficina da Língua Kokama em todo o Amazonas. Iniciou estas oficinas em Manaus e foi convidado a realizar outras oficinas nas aldeias e comunidades kokama do Médio e do Alto Solimões nos municípios de Fonte Boa, Santo Antonio do Içá, São Paulo de Olivença, Benjamin e Tabatinga.

11 A comunidade de Bugaio no município de Jutaí solicitou por meio de um projeto enviado para o PDPI (Projeto Demonstrativo dos Povos Indígenas), a "revitalização" da língua Kokama em sua comunidade. Esse processo está ocorrendo com presença ou monitoramento do linguista do CIMI. 
suas comunidades como "escolas Kokama". O fator educacional torna-se um instrumento que assegura os direitos territoriais e dirime dúvidas, porventura existentes, sobre seu domínio. O MEC atendeu a esta reivindicação das comunidades e as escolas que eram não indígenas foram transformadas em escolas indígenas, com frequência superior a 400 alunos, garantindo a territorialidade específica em que se localizam, senão vejamos:

\begin{tabular}{|c|l|l|c|c|}
\hline$N^{o}$ & Comunidade & Escola & Etnia & No de alunos \\
\hline 1 & Porto Lutador & Rano Raimuni & Kokama & 41 \\
\hline 2 & Bairro União & Sando Ranzeco Ra Patacon & Kokama & 67 \\
\hline 3 & Curupati & São José & Kokama & 46 \\
\hline 4 & Boa Esperança & São Sebastião & Kokama & 15 \\
\hline 5 & Bairro União & Ruqui Umi Katiri & Kokama & 69 \\
\hline 6 & Bom Jesus III & Darcio Rabelo & Kokama & 15 \\
\hline 7 & Santa Rita do Well & Gilberto Mestrinho & Kokama & 31 \\
\hline 8 & Colonia São Sebastião & Edson Pereira Arcanjo & Kokama & 103 \\
\hline 9 & Santos Anjos & São João Apóstolo & Kokama & 25 \\
\hline
\end{tabular}

Total: 412 alunos kokama estudando em escolas indígena Kokama em S.P. de Olivença. FONTE: Dados da Secretaria Municipal de Educação e Cultura - SEMEC de São Paulo de Olivença, 2011.

O reconhecimento étnico tanto é fortalecido pelo reconhecimento oficial das escolas Kokama pelo MEC, quanto pela instituição de concurso municipal para professor indígena Kokama, Kaixana, Kambeba e Ticuna. Nessa perspectiva, a escola se torna um campo em que são tomadas decisões fundamentais no reforço das relações associativas, criando condições para o surgimento de novas mobilizações em resposta ao estado de "exclusão" em que se encontram. Do mesmo modo, é visualizada, no plano comunitário, a pormenorização de cada problema que permeia as ações das quais participa o professor indígena.

A escola indígena inicia, portanto, o seu processo de construção de um espaço social próprio, em um complexo campo de disputas. Para Bourdieu (2006), essas lutas ocorrem dentro de um campo político no qual se opõem os agentes sociais, numa "tomada de posição sobre este ou aquele problema político” (Bourdieu 2006:156).

Nesse sentido a formação do professor torna-se essencial para que o fortalecimento da identidade Kokama seja reafirmado. Os professores Kokama 
estão passando por um processo de formação do ensino superior, por meio da "Pedagogia-Licenciatura Intercultural Indígena", curso oferecido, atualmente, pela Universidade do Estado do Amazonas- UEA e pelo curso de Licenciatura em Educação Escolar Indígena com Habilitação em Letras em Língua Kokama e Espanhola também realizado pela Organização dos Professores Tikuna Bilíngue - OGPTB e UEA.

Vale ressaltar que o ensino da língua Kokama em sala de aula está ocorrendo gradativamente, pois os próprios professores estão passando por uma formação mais completa na língua Kokama. A turma, que estava fazendo a Licenciatura em Letras em Língua Kokama e Espanhol, com os seus professores, produziram materiais didáticos em mídias, como DVDs e CDs com histórias, mitos, diálogos, grafismos, dança e músicas em kokama. Esses materiais são disponibilizados para as comunidades Kokama, que estão em processo de revitalização da língua e da cultura, de Manaus a Atalaia do Norte. A outra turma de professores Kokama está fazendo a Pedagogia - Licenciatura Intercultural Indígena. Ambos os cursos são oferecidos pela Universidade do Estado do Amazonas - UEA.

\section{Ensino da língua Kokama pelos professores indígenas}

A língua se tornou, para as comunidades indígenas na cidade, um instrumento básico nas lutas pela classificação. $O$ caso da diversidade linguística que ocorre em São Gabriel da Cachoeira bem explicita isto (Faria 2003). Apesar das diferentes línguas indígenas faladas, os povos indígenas do local se mobilizaram para cooficializar três línguas indígenas (Tukano, Baniwa e Nheengatu) e conseguiram ademais que os poderes municipais passassem a discutir a implementação do Decreto $\mathrm{n}^{\circ}$ 6.040, assinado pelo Presidente da República em 07 de fevereiro de 2007, que institui a Política Nacional de Desenvolvimento Sustentável dos Povos e Comunidades Tradicionais consoante a Convenção 169 da O.I.T. e cujo inciso XIV do Art. 1 assevera a "preservação dos direitos culturais, o exercício de práticas comunitárias, a memória cultural e a identidade racial e étnica." e tem fundamentado as reivindicações de cooficialização de línguas indígenas ${ }^{12}$ no âmbito municipal (Almeida 2007:11).

12 A aprovação desta lei que cooficializa o Tukano, o Baniwa e o Nheengatu no Alto Rio Negro, Estado do Amazonas, região mais plurilíngue das Américas, onde são faladas 23 (vinte e três) línguas indígenas, tem reforçado as reivindicações de reconhecimento da diversidade linguística. Este tipo de reconhecimento sempre foi menosprezado pelas políticas educacionais. Foi inclusive contestado pela política de "Nacionalização do Ensino", iniciada pela ditadura do Estado Novo (1937-1945), que reprimiu duramente tanto as línguas alóctones, praticadas pelos imigrantes europeus e pelos ciganos, quanto as línguas autóctones, dos povos indígenas. A partir da aprovação desta lei de cooficialização 
Esse decreto estabelece que os órgãos públicos tenham suas informações traduzidas nessas três línguas e que disponibilizem pessoas com tais conhecimentos das línguas cooficiais para prestarem serviços às comunidades indígenas. Nesse sentido, a população pode visualizar os nomes de ruas, as placas de orientação e determinados anúncios escritos nos três idiomas, Tukano, Baniwa e Nheengatu.

Assim como os povos indígenas conseguiram dar outro sentido à escola de inspiração colonial que os massacrou, deram outro sentido à língua geral, o nheengatu, instrumento utilizado pelas ordens religiosas também para dizimálos. Atualmente, ela é mais um instrumento na luta pela reivindicação de seus direitos.

Aprender a falar ou ensinar a língua indígena é mais do que afirmar a identidade étnica, é estar politicamente demarcando um espaço social ou reconquistando tal espaço no âmbito do direito, diante da sociedade. Para Almeida (2007), os povos indígenas têm utilizado a língua como forma de controlar e obter mais autonomia para se relacionar com os órgãos governamentais e não governamentais, neutralizando ações que caracterizam uma nova forma de tutela.

[...] afirmação linguística estariam também as tentativas dos povos indígenas em controlar de maneira mais autônoma suas relações com o Estado e com as instituições privadas (entidades confessionais, ong's, empresas), cujas ações mediadoras configuram formas renovadas de tutela. (Almeida 2007:15).

A língua está se tornando um dos principais instrumentos dos povos indígenas contra as diferentes formas de tutela que o Estado e as instituições privadas tem para controlar o movimento indígena organizado.

Os Kokama estão em processo de tornar ao cotidiano a sua língua e seus rituais. Sua língua foi considerada por muitos linguistas como uma "língua desaparecida”. A língua Kokama no Brasil estava tão somente na memória dos mais velhos. Foi registrada por alguns estudiosos e com a ajuda de pesquisadores conseguiu ser transformada em material didático que está sendo utilizado no processo de recolocar na vida cotidiana a língua Kokama.

de línguas indígenas em São Gabriel da Cachoeira tem-se outras situações similares, envolvendo inclusive línguas alóctones, como o reconhecimento da língua pomerana no Município de Santa Maria de Jetibá, em novembro de 2008, no Estado do Espírito Santo. O reconhecimento no plano municipal tem funcionado como um instrumento de pressão sobre o Legislativo e seu resultado mais recente e expressivo concerne ao Decreto $n$. $^{\circ}$ 7.387 de 9 de dezembro de 2010, assinado pelo Presidente da República, que instituiu o Inventário Nacional de Diversidade Linguística. O art. I deste decreto abre a possibilidade de um amplo "reconhecimento e valorização das línguas portadoras de referencia à identidade, à ação e à memória dos diferentes grupos formadores da sociedade brasileira”. 
Aprender ou reaprender e lembrar ou relembar refletem um processo que está em curso, acontecendo no aprendizado da língua Kokama. A afirmação de intérpretes de que "o fato de a língua dos seus pais ser ensinada como segunda língua é irrelevante” (Viegas 2010:30), parece não surtir efeito. Ora, esta língua é considerada como primeira língua para os Kokama.

O ensino da língua Kokama é um desafio, pois a priori fora classificada para muitos linguistas como sendo do troco linguístico Tupí. No final da década de 1950 Rodrigues chega a concordar com as afirmações sobre a língua kokama ser do tronco linguístico Tupí, mas em 1985 Rodrigues retoma as discussões sobre a classificação desta língua e levanta a hipótese de que esta língua poderia não pertencer a esta família. Em 1995, CABRAL comprovou ao comparar a língua kokama com a língua Tupinambá por meio do método histórico comparativo que a língua kokama continha muitos elementos de outras línguas, como as do aruak, tupy e kechua, ou seja era uma língua "crioula" resultado do contato de várias línguas. Nesse sentido, o material didático da língua kokama é produzido de duas formas: uma com o alfabeto peruano, materiais produzidos para professores indígenas do Peru, mas que são socializados com os kokama brasileiros e o outro com o alfabeto brasileiro com adaptações realizadas pelas linguistas Ana Suely Cabral e Chandra Wood Viegas produzidos na OGPTB (2010) e pelo linguista do CIMI materiais produzidos nas próprias comunidades indígenas.

$\mathrm{Na}$ maioria das comunidades ou aldeias kokama ainda não há uma reivindicação da língua kokama se cooficializar, mas as comunidades esperam que a formação dos professores sirva para ajudá-los a melhor orientar o ensino da língua em parceria com os mais velhos falantes. Apenas em São Paulo de Olivença as comunidades estão se organizando para solicitar o ensino da língua Kokama como disciplina permanente nas escolas Kokama.

Dessa forma, os Kokama superam os diferentes processos de estigmatização, por meio de sua organização política em torno da escola, efetivada pelo fortalecimento de sua identidade étnica. Fazendo-se reconhecer em diversas instancias da sociedade conseguiram superar os períodos de "luta" e de "luto" de sua história e ganham força em suas reivindicações nas questões referentes à terra, à saúde e à educação. $\mathrm{O}$ conflito com o povo Ticuna, historicamente descrito, assume outra configuração. Novas dinâmicas na relação entre estes povos, que estão em constante colaboração no campo político das organizações indígenas no Alto Solimões, apontam para um futuro de ações conjuntas. Esta visão prospectiva, que emerge hoje com bastante força nas relações entre estes dois povos, rompe com o passado de profundas desigualdades e redesenha novas fronteiras políticas, que concorrem para a persistência de tais identidades coletivas, num futuro de autonomia e de coexistência linguística. 


\section{Referências}

Almeida, Alfredo Wagner Berno de. 2008. O mapeamento social, os conflitos e o censo: uma apresentação das primeiras dificuldades. In: Alfredo Wagner Berno de Almeida e Glademir Sales dos Santos (Orgs.). Estigmatização e território: Mapeamento situacional dos indígenas em Manaus. Manaus: Projeto Nova Cartografia Social da Amazônia, Editora da UFAM. p.19-33.

Almeida, Alfredo Wagner Berno de. 2007. Os movimentos indígenas e a autoconsciência cultural. In: Alfredo Wagner Berno de Almeida (Org.). Terra das Línguas: Lei Municipal de Oficialização de Línguas Indígenas. São Gabriel da Cachoeira, Amazonas. Manaus. PPGSCA, Ufam, Fund. Ford. p.9-29.

Barth, Fredrik. 2000. O guru, o iniciador. e outras variações antropológicas. Tradução de John Cunha Comerford. Rio de Janeiro: Contra Capa. p. 25-67.

Bourdieu, Pierre. O poder simbólico. 9. ed. Tradução de Fernando Tomaz. Rio de Janeiro: Bertrand Brasil, 2006.

Cabral, Ana Suelly A. C. 1995. Contacta - induced language change in the Western Amazon: the non-genetic origin of the Kokama language. Tese (doutorado em Linguística) - Univer. of Pittsburg, Pittsburg. 415p.

D’Ávila, Miguel. Quem são os Kokamas?: Disponível em: <http://jornaldedebates.uol. com.br/debate/Amazônia-nossa/artigo/quem-são-kokamas/12811>.

Deleuze, Gilles. 2005. As estratégias ou o não-estratificado: o pensamento do lado de fora (poder) In: . Foucault. Tradução Cláudia Sant'Anna Martins; revisão da tradução Renato Ribeiro. São Paulo: Brasiliense. p78-79.

Faria, Ivani Ferreira de. 2003. Território e Territorialidades Indígenas do Alto Rio negro. Manaus: Editora da Universidade Federal do Amazonas.

Freitas, Marcos Antonio Braga de. 2002. O povo kokama: Um caso de reafirmação de identidade étnica. Dissertação (mestrado) - Programa de Pós-Graduação em Sociedade e Cultura na Amazônia, Universidade Federal do Amazonas, Manaus.

Oliveira, João Pacheco.1987. “O Nosso governo”. Os ticuna e o regime tutelar. São Paulo: Marco Zero; Brasília, DF: MCT.

Pereira, Marcina. 2010. Entrevista realizada no bairro da Independência em Santo Antonio do Içá/AM.

Rodrigues, Aryon Dall'Igna. 1984/1985. Relações internas na Família linguística TupíGuaraní. Revista de Antropologia, separata dos volumes XXVII/XXVIII. São Paulo.

Rubim, Altaci Corrêa. 2011. Identidade dos Professores Indígenas e Processo de Territorialização/Manaus-Am. Dissertação (mestrado) - Programa de Pósgraduação em Sociedade e Cultura na Amazônia da Universidade Federal do Amazonas, Manaus.

Viegas, Chandra Wood. 2010. Natureza e direções das mudanças lingüísticas observadas entre os últimos falantes do kokáma nativos do Brasil. Dissertação (mestrado) - Programa de Pós-graduação em Lingüística da Universidade de Brasília. 